\title{
Genetic, phenotypic and functional variation within a Glomus geosporum isolate cultivated with or without the stress of a highly alkaline anthropogenic sediment
}

\author{
Rui S. Oliveira ${ }^{\mathrm{a}}$, Louisa Robinson Boyer ${ }^{\mathrm{b}}$, Maria F. Carvalho ${ }^{\mathrm{a}}$, Peter Jeffries ${ }^{\mathrm{b}}$, Miroslav Vosátka ${ }^{\mathrm{c}}$, \\ Paula M.L. Castro ${ }^{\mathrm{a}, *}$, John C. Dodd $^{\mathrm{d}}$ \\ ${ }^{a}$ CBQF/Escola Superior de Biotecnologia, Universidade Católica Portuguesa, Rua Dr. António Bernardino de Almeida, 4200-072 Porto, Portugal \\ ${ }^{\mathrm{b}}$ Research School of Biosciences, University of Kent, Canterbury, Kent CT2 7NJ, United Kingdom \\ ${ }^{\mathrm{c}}$ Institute of Botany, Academy of Sciences of the Czech Republic, 25243 Pruhonice, Czech Republic \\ dinternational Institute of Biotechnology, 1-19 Innovation Building 1000, Kent Science Park, Sittingbourne, Kent ME9 8EF, United Kingdom
}

Keywords:

AMF inoculum production

Arbuscular mycorrhizal fungi

Environmental stress

Genetic phenotypic and functional variation

Highly alkaline sediment

Intra-isolate variation

\begin{abstract}
A B S T R A C T
Genetic, phenotypic and functional variation in a Glomus geosporum isolate obtained from a highly alkaline anthropogenic sediment was investigated. Two cultivation lineages of G. geosporum (BEG199 and BEG211) were created by sub-culturing with or without the stress of the sediment. Genetic variation was assessed on spores from both cultivation lineages in the large sub-unit rRNA gene D2 region using PCR-single strand conformational polymorphism (PCR-SSCP) and sequencing. Phenotypical and functional variation of the cultivation lineages were assessed after inoculation onto Conyza bilbaoana. The sequence diversity obtained in G. geosporum BEG211 was significantly different from that obtained in G. geosporum BEG199. Glomus geosporum BEG199 was more effective than G. geosporum BEG211 in promoting the growth of $C$. bilbaoana in inert substrate and in increasing its leaf phosphorus concentration when the plant was grown in sediment. After inoculation onto C. bilbaoana, G. geosporum BEG199 colonised the roots to a greater extent, produced a significantly larger number of spores and presented a greater length of extraradical mycelium than G. geosporum BEG211. The results indicate that environmental conditions under which arbuscular mycorrhizal fungi (AMF) are cultivated can influence their effects in host plants. Also, AMF might quickly lose gained-tolerance to environmental stresses when maintained without the selective pressure of those stresses. This study has implications for the production of commercial inoculum of AMF and for the maintenance of AMF cultures. The results indicate that inoculum of AMF should be produced and AMF cultures should be maintained in substrates or media containing the original edaphic stresses.
\end{abstract}

\section{Introduction}

Arbuscular mycorrhizal fungi (AMF), from the Glomeromycota, are a ubiquitous group of soil organisms that form symbiotic associations with the roots of the majority of terrestrial plant species (Smith and Read, 2008). Arbuscular mycorrhizal fungi are considered to be ecologically important as it has been shown that their diversity determines plant diversity and ecosystem productivity (van der Heijden et al., 1998). Arbuscular mycorrhizal fungi are also becoming economically important as there has been a growing interest in exploiting these organisms for commercial applications in agriculture, forestry and restoration schemes; and the number of companies producing commercial inoculum of AMF has increased over the last decade (von Alten et

\footnotetext{
* Corresponding author. Tel.: +351 225580067; fax: +351 225090351.

E-mail address: plcastro@esb.ucp.pt (Paula M.L. Castro).
}

al., 2002; Vosátka and Dodd, 2002; Gianinazzi and Vosátka, 2004).

Despite the great importance of these fungi, their genetics and relationship between genetic and functional diversity are still poorly understood (Sanders, 2002; Munkvold et al., 2004; Sanders, 2004). However, the recent application of molecular biological techniques has led to important advances.

Unusually high ribosomal gene sequence diversity (Sanders et al., 1995; Lloyd-MacGilp et al., 1996; Pringle et al., 2000; Clapp et al., 2001; Rodriguez et al., 2001, 2005; Corradi et al., 2007), mitochondrial gene sequence diversity (Börstler et al., 2008) and protein-coding gene sequence diversity (Kuhn et al., 2001; Helgason et al., 2003; Corradi et al., 2004) have been found to exist within single isolates of several AMF species and even within single spores of AMF. Although DNA polymorphism in AMF spores has been widely reported, little is known on how genetic variability influences the effects of AMF in their host plants (Sanders, 2004; Koch et al., 2006). Kuhn et al. (2001) suggested that different 
functional variants of a gene could exist in the same AMF isolate, whilst Koch et al. (2004) indicated that variation in rates of hyphal growth and spore production in Glomus intraradices was due to genetic differences among isolates of the population.

If different functional variants of a gene exist in the same AMF isolate, it is critical to understand the driving forces of their expression (Sanders, 2002, 2004). One of these forces may be the selective pressure of environment to which AMF are exposed. One possibility is that different variants are expressed in different environments. This could explain the wide range of different environments in which AMF can live (Brundrett, 1991) and their plasticity in adapting to new edaphic conditions (Sylvia and Williams, 1992; Enkhtuya et al., 2000; Oliveira et al., 2001, 2005b).

Clapp et al. (2001) described genetic diversity in AMF maintained under different culture conditions. Two G. coronatum isolates BEG28T and F097 were isolated from a field site in Italy. The BEG28T isolate was subsequently sub-cultured in both England (BEG28K) and Scotland (BEG28W), whilst F097 remained in Italy. Interestingly, several rRNA gene sequences appeared to be lost from BEG28T and BEG28K but were retained by BEG28W. Five sequences were found to be common in the F097 and BEG28W isolates. Clapp et al. (2001) suggested that the loss of sequences may reflect differences in culturing conditions or selection via subsequent sub-culturing. This may indicate that there is a gradual selection as the AMF adapts to the prevailing environmental conditions and suggests that genetic diversity can change rapidly under different culturing conditions and supports the genetic drift as noted by Wyss and Bonfante (1993) in G. mosseae BEG12, which had been maintained in different European laboratories.

Feldmann (1998) showed that after sub-culturing AMF for prolonged periods of time they behaved differently on plants, that is their functionality and efficacy changed over time, indicating that genetic drift had occurred.

Sub-culturing conditions have been shown to influence the efficacy of AMF in promoting plant growth and heavy metal tolerance and accumulation (Malcová et al., 2003; Rydlová and Vosátka, 2003; Sudová et al., 2007). The ability of a Glomus intraradices isolated from a Pb-contaminated soil to support plant growth and to prevent $\mathrm{Pb}$ translocation from the roots to the shoots of Agrostis capillaris decreased after 13 months of cultivation in a metal-free substrate (Rydlová and Vosátka, 2003). Two years of heavy metal-free cultivation of a Glomus sp. isolated from Mncontaminated soil was shown to reduce its tolerance to $\mathrm{Mn}$ (Malcová et al., 2003). Overall, these studies show that AMF can reduce their tolerance when sub-cultured without the stress of heavy metals. It thus seems possible that the sub-culturing conditions can have an effect on the AMF phenotype, which could in turn lead to a change in their functionality. The aim of the present work was to investigate variation at the genetic, phenotypic and functional level of a Glomus geosporum isolate cultivated with or without the stress of the highly alkaline anthropogenic environment from where it was originally isolated.

\section{Materials and methods}

\subsection{Fungal isolation}

The strain of Glomus geosporum studied in this work was isolated from a 40-year-old anthropogenic site containing a highly alkaline sediment. The site was a 10 -ha sedimentation pond located in the industrial complex of Estarreja, Northern Portugal $\left(40^{\circ} 46^{\prime} 30^{\prime \prime} \mathrm{N}, 08^{\circ} 35^{\prime} 04^{\prime \prime} \mathrm{W}\right)$ where 300,000 ton of solid residues had been deposited as waste from the production of acetylene and polyvinyl chloride. Extreme alkalinity, high salinity and low soil nutrient levels of the sediment appeared to be the main stresses for plants and AMF on the site (Oliveira et al., 2005a; b). A trap culture was established in July 2000 using Juncus effusus L. roots collected from the site. The root ball $(4-6 \mathrm{~cm}$ diameter with attached sediment) was placed into a $16 \mathrm{~cm}$ (diameter) $\times 12 \mathrm{~cm}$ (depth) plastic pot, and the remaining volume filled with a 1:5 (v/v) mixture of alkaline sediment collected from the site (from the uppermost 5-cm layer and sieved through a 3-mm mesh) and zeolite (clinoptilolite $1.0-2.5 \mathrm{~mm}$, Chemko, SK), autoclaved twice at $121^{\circ} \mathrm{C}$ for $25 \mathrm{~min}$ on two consecutive days. Seeds of maize (Zea mays L.) and red clover (Trifolium pratense L.) were surfacesterilised with $0.5 \%(\mathrm{v} / \mathrm{v}) \mathrm{NaOCl}$ for $15 \mathrm{~min}$ and sown together in the soil around the root ball after the shoots were excised. Clover continued to grow throughout the experiment, while new maize seeds were resown every 4 months. The trap culture was grown in a controlled greenhouse ( $16 \mathrm{~h}$ photoperiod, with supplementary metal halide $400 \mathrm{~W}$ lighting, $600-800 \mu \mathrm{mol} \mathrm{m} \mathrm{m}^{-2} \mathrm{~s}^{-1}$ photosynthetically active radiation, $15-39{ }^{\circ} \mathrm{C}$ temperature range, $60-85 \%$ relative humidity range), watered every $2 \mathrm{~d}$ with deionised water and supplied with nutrients (without P) once per week using $1.4 \mathrm{~g} \mathrm{l}^{-1}$ Vitafeed 102 (Vitax, Leicester, UK) with trace elements. After 16 months, four $50-\mathrm{cm}^{3}$ cores of substrate were removed from the trap culture and spores of AMF were extracted according to Allen et al. (1979). Identification of AMF species was based on spore morphology under a stereomicroscope (Olympus SZ60, Japan) and on diagnostic slides under a compound microscope (Olympus BX60, Japan) (www.kent.ac.uk/bio/beg/englishhomepage.htm under protocols). Fifty apparently healthy spores were used to start a pure multispore pot culture of $G$. geosporum, which was maintained under the same conditions (pot size, substrate mixture, host plant species and plant growth conditions) as described above.

\subsection{Cultivation lineages of Glomus geosporum}

After 6 months, four $50-\mathrm{cm}^{3}$ cores of substrate were removed from the multispore pot culture of G. geosporum, spores of AMF were extracted and their identity verified as described above to confirm the monospecificity of the culture. Extracted spores were used to initiate two cultivation lineages of G. geosporum. In one lineage (OSL-original substrate lineage), G. geosporum was cultivated in a 1:5 (v/v) mixture of the original alkaline sediment and zeolite (autoclaved twice at $121^{\circ} \mathrm{C}$ for $25 \mathrm{~min}$ on two consecutive days) and in the other lineage (ISL-inert substrate lineage), G. geosporum was cultivated in an inert autoclaved substrate (zeolite). The chemical and physical characteristics of the sediment and the zeolite are given in Table 1 and were determined as described in Oliveira et al. (2005a). The ratio of 1:5 (v/v) sediment:zeolite used in the cultivation substrate of the OSL was sufficient to maintain the original high $\mathrm{pH}$ of the sediment. Four multispore pot cultures were established for each lineage using the same pot type as described above, by placing a total of 50

Table 1

Chemical and physical characteristics of the alkaline sediment and the zeolite.

\begin{tabular}{lll}
\hline & Sediment & Zeolite \\
\hline $\mathrm{pH}\left(\mathrm{H}_{2} \mathrm{O}\right)$ & 11.8 & 7.0 \\
$\mathrm{pH}\left(\mathrm{CaCl}_{2}\right)$ & 11.6 & 6.6 \\
$\mathrm{pH}(\mathrm{KCl})$ & 12.1 & 5.6 \\
Conductivity $\left(\mu \mathrm{Scm}^{-1}\right)$ & 5980 & 120 \\
Total C $(\%)$ & 8.9 & 0.1 \\
Total $\mathrm{N}(\%)$ & 0.23 & $<0.01$ \\
& & \\
Extractable values $\left(\mathrm{mg} \mathrm{kg}^{-1}\right)$ & 10.5 & 0.5 \\
$\mathrm{P}$ & 52.0 & 9747 \\
$\mathrm{~K}$ & 19.0 & 361.6 \\
$\mathrm{Na}$ & 60.4 & 178.0 \\
$\mathrm{Mg}$ & 5721 & 13330 \\
$\mathrm{Ca}$ & & \\
\hline
\end{tabular}


apparently healthy spores per pot on the surface of germinating roots of red clover and maize seedlings (two seedlings of each plant species per pot). Seeds of red clover and maize were surfacesterilised as described above and pre-germinated in plastic trays containing fine sand (AGS 0.5-1.0, Areipor, Bucelas, Portugal) preautoclaved twice $\left(121^{\circ} \mathrm{C}\right.$ for $25 \mathrm{~min}$ ) on two consecutive days. Clover continued to grow throughout the experiment, while new maize seeds were resown every 4 months. The generation time of G. geosporum ranges between 3.5 and 7 months, depending on the season and substrate, both of which may influence plant growth rate and fungal development (Oliveira et al., unpublished). Microbial populations from the original non-sterile sediment and zeolite mixture and non-sterile zeolite were reintroduced to the OSL and ISL pots, respectively, by adding $30 \mathrm{ml}$ of filtrate (Whatman No. 1) to each pot. The filtrate was obtained from $300 \mathrm{~g}$ of non-sterile substrate shaken for $2 \mathrm{~h}$ in $3 \mathrm{l}$ of sterile deionised water. The plants were grown under the same plant growth conditions (greenhouse, watering and nutrient supply regime) as described above for the trap culture. The pot cultures were periodically rotated to different bench positions to minimise differences due to their location in the greenhouse. After 14 months, roots of red clover and maize were washed to remove adhered substrate, fine lateral roots were cut into $1-\mathrm{cm}$ pieces and stained using a modified Phillips and Hayman (1970) protocol (Oliveira et al., 2005b). Percentage root length colonised (\% RLC) by AMF was assessed for each host plant species by using a gridline intersect method (Giovannetti and Mosse, 1980). The substrate was homogenised and the length of the extraradical mycelium (ERM) of AMF was evaluated in $5 \mathrm{~g}$ of air-dried sub-samples. The length of ERM was assessed by a modified membrane filtration technique (Jakobsen et al., 1992), using the grid-line intersect method under a compound microscope, with an ocular grid at $200 \times$ magnification (Brundrett et al., 1994) and expressed in $\mathrm{m}$ of hyphae per $1 \mathrm{~g}$ of air-dried substrate. Spores of AMF were extracted from $5 \mathrm{~g}$ of air-dried sub-samples as described above, placed in a Petri dish and only apparently healthy spores were counted under a stereomicroscope at $100 \times$ magnification or less. The number of spores was expressed in spores per $1 \mathrm{~g}$ of air-dried substrate. The identity of G. geosporum spores was verified and after confirming the monospecificity of the OSL and ISL cultures, they were registered in the International Bank for the Glomeromycota (IBG; formerly BEG-La Banque Européenne des Glomales, www.kent.ac.uk/bio/beg), and given the codes BEG199 and BEG211, respectively.

\subsection{Spore germination test}

One multispore pot culture of each cultivation lineage of $G$. geosporum (BEG199 and BEG211) was randomly chosen and $150 \mathrm{~g}$ of substrate containing spores were removed from the pot and stored in the dark at $4{ }^{\circ} \mathrm{C}$ for $15 \mathrm{~d}$ to synchronise germination. Spores were extracted as described above and thoroughly rinsed with deionised water. Spore germination was assessed according to the procedure of Brundrett and Juniper (1995), following a randomised experimental design with two factors: G. geosporum cultivation lineage (BEG199 or BEG211) and germination matrix (sediment or zeolite). Each treatment was replicated three times. Square Petri dishes $(100 \mathrm{~mm} \times 100 \mathrm{~mm})$ were packed with either moist autoclaved sediment or zeolite. Forty $10 \mathrm{~mm} \times 10 \mathrm{~mm}$ square pieces of nitrocellulose membrane filter $(0.40 \mu \mathrm{m}$ pore size, Pragopore, Pragochema Ltd., Czech Republic) were laid on the germination matrix of each Petri dish and one apparently healthy spore was placed in the centre of each membrane filter. Each Petri dish containing 40 spores was treated as a replicate. Dishes were sealed and incubated in the dark at $25^{\circ} \mathrm{C}$. After $15 \mathrm{~d}$, membranes were stained with a $0.05 \%(\mathrm{w} / \mathrm{v})$ Trypan blue solution and examined under a compound microscope. The percentage of spores germinated in each dish was recorded. Germination was considered to have occurred if a germ tube was clearly visible.

\subsection{DNA analyses of Glomus geosporum lineages}

\subsubsection{DNA extraction, amplification and cloning}

Spores of G. geosporum BEG199 and G. geosporum BEG211 were extracted as described above from the same two multispore pot cultures used for the spore germination test. Apparently healthy spores from each cultivation lineage were selected, surface-sterilised and their DNA extracted from multi-spore preparations (80 spores) as described by Clapp et al. (2001). PCR amplification of the LSU rRNA gene D2 region was conducted with the primers ALF01 (Clapp et al., 2001) and NDL22 (Van Tuinen et al., 1998) using the same PCR parameters as previously described in Clapp et al. (2001). Next, amplified products were purified using Wizard PCR Preps (Promega, Madison, WI, USA), ligated into the vector pGEM-T Easy (Promega) cells and transformed into competent Escherichia coli JM109 (Promega) following the manufacturer's instructions. Recombinant colonies were selected by blue/white screening and the presence of the correct inserts detected by PCR amplification directly from white colonies, with the same primers and PCR parameters used for the original DNA amplification.

\subsubsection{PCR-SSCP, sequencing and phylogenetic analysis}

Fifty-five and 50 cloned inserts from G. geosporum BEG199 and G. geosporum BEG211, respectively, were screened for sequence variation using PCR-single-strand conformational polymorphism (PCR-SSCP) of cloned amplicons, and the frequency of each SSCP type recorded. PCR-SSCP was carried out as described by Clapp et al. (2001). Recombinant plasmids from representative clones of each SSCP type were extracted from bacterial clones, purified using Wizard Minipreps (Promega) and their inserts sequenced as described by Clapp et al. (2001). All obtained sequences were checked against existing sequences using BLAST (www.ncbi.nlm.nih.gov/BLAST). Previously reported sequences (Clapp et al., 2001; Rodriguez et al., 2001, 2005), along with sequences (from Glomus and species from the Gigasporaceae and Acaulosporaceae) obtained from GenBank (www.ncbi.nlm.nih.gov), were also included in the alignment. In addition, outgroups were used in this analysis including basidiomycete, ascomycete and zygomycete sequences. The D2 region sequences were aligned using ClustalW (Thompson et al., 1997) and phylogenetic analysis was conducted using PAUP 4.0b10 (Swofford, 1999) as described in Clapp et al. (2001). Analyses were carried out using both neighbour-joining (Saitou and Nei, 1987) and maximum parsimony (Swofford, 1999). Maximum parsimony analysis was performed using heuristic search options with 100 bootstrap replications (Felsenstein, 1985), branch swapping by tree-bisection-reconnection, branches able to collapse to yield polytomies, and with parsimony uninformative characters excluded. Single, unambiguously aligned gaps were treated as fifth character states. Trees were displayed using Treeview (Page, 1996).

\subsection{Symbiotic efficacy of Glomus geosporum lineages}

The efficacy of the two G. geosporum lineages was assessed in symbiosis with Conyza bilbaoana J. Rémy. This plant species was chosen because it was the dominant plant species at the anthropogenic study site, had a high arbuscular mycorrhizal dependency and is a potential target plant to be inoculated with AMF and used for phytorestoration (Oliveira et al., 2005b). Seeds of C. bilbaoana were collected from the site in order to obtain plants of local provenance and adapted to the alkaline sediment. They were 
surface-sterilised with $0.5 \%(\mathrm{v} / \mathrm{v}) \mathrm{NaOCl}$ for $5 \mathrm{~min}$ and pregerminated in the greenhouse in fine sand as described above for red clover and maize. After $35 \mathrm{~d}$, seedlings of similar size were transplanted singly into $200-\mathrm{cm}^{3}$ pots. Half of the pots contained autoclaved alkaline sediment while the other half contained autoclaved zeolite. Microbial populations from the original nonsterile substrates were reintroduced to each pot by adding $20 \mathrm{ml}$ of filtrate (Whatman No. 1), obtained as described above for the cultivation lineages. For each substrate (sediment and zeolite), there were three treatments: non-inoculated controls, plants individually inoculated with G. geosporum BEG199 or G. geosporum BEG211. All treatments were replicated six times. Spores of G. geosporum BEG199 and G. geosporum BEG211 were extracted as described above from the same two multispore pot cultures (one of each cultivation lineage) used for the spore germination test and for the DNA analyses. Inoculation was performed by placing a number of apparently healthy spores on the surface of the roots of $C$. bilbaoana seedlings. The number of inoculated spores was calculated according to the percentages obtained in the spore germination test of G. geosporum BEG199 and G. geosporum BEG211 in each substrate and inoculation was performed in order to have the same initial number of germinating spores in all the mycorrhizal treatments, i.e., 25 germinating spores per pot. Five millilitres of filtrate (Whatman No. 1) from G. geosporum BEG199 and $G$. geosporum BEG211 inocula mixture were added to all pots to eliminate differences in microbial populations introduced with the AMF spores (Koide and $\mathrm{Li}, 1989$ ). The filtrate was prepared from $100 \mathrm{~g}$ of an inoculum mixture ( $50 \mathrm{~g}$ of each $\mathrm{G}$. geosporum cultivation lineage) shaken for $2 \mathrm{~h}$ in 21 of autoclaved deionised water. The plants were grown in the greenhouse and watered every $2 \mathrm{~d}$ with deionised water. The plants growing in zeolite were supplied with nutrients (without P) once a week using $1.4 \mathrm{~g} \mathrm{l}^{-1}$ Vitafeed 102 with trace elements. Pots with different treatments were periodically rotated to different bench positions to minimise differences due to their location in the greenhouse. Pots with different treatments were kept separately to prevent cross contamination.

\subsubsection{Mycorrhizal parameters}

One sample containing substrate and lateral roots was removed from each pot using a $15-\mathrm{cm}^{3}$ core borer after 2, 3, 4 and 7 months. Roots were separated from the substrate, cut into $1-\mathrm{cm}$ pieces and stained using a modified Phillips and Hayman (1970) protocol (Oliveira et al., 2005b). Stained root pieces were mounted on glass slides and examined with a compound microscope $(100-400 \times)$ to assess the frequency $(F \%)$ and intensity $(M \%)$ of arbuscular mycorrhizal colonisation in the root system and the arbuscule $(A \%)$ and vesicle $(V \%)$ abundance in the root system, according to the method described by Trouvelot et al. (1986). The substrate sample was homogenised and air-dried and $5 \mathrm{~g}$ were used to evaluate the length of the ERM of AMF as described above. The length of the ERM was expressed in $\mathrm{m}$ of hyphae per $1 \mathrm{~g}$ of air-dried substrate. Spores of AMF were extracted from $5 \mathrm{~g}$ of the air-dried substrate sample as described above and only apparently healthy spores (rigid and non hollow) were counted in a Petri dish under a stereomicroscope at $100 \times$ magnification or less. The number of spores was expressed in spores per $1 \mathrm{~g}$ of air-dried substrate. The identity of G. geosporum and the monospecificity of the spores were confirmed.

\subsubsection{Plant parameters}

After 7 months of growth, the root system of $C$. bilbaoana was separated from the shoot and washed to remove adhered substrate. Roots and shoots were dried at $70^{\circ} \mathrm{C}$ for $48 \mathrm{~h}$ and weighed. Oven-dried leaves were finely ground and $0.3 \mathrm{~g}$ of material was digested according to Novozamsky et al. (1983). Phosphorus (P) concentration in leaves was determined by colorimetry (Helios Gamma,Unicam, Cambridge, UK) (Walinga et al., 1989). Leaf P concentration was not determined in the noninoculated control plants because not enough plant material was available.

\subsection{Statistical analysis}

The data from the spore germination test and from plant biomasses were analysed using two-way and one-way analysis of variance (ANOVA), respectively. Spore germination data were arcsine transformed to satisfy ANOVA assumptions. When a significant $F$-value was obtained $(P<0.05)$, treatment means were compared using the Duncan's multiple range test. The frequencies of sequence variants of $G$. geosporum BEG211 and G. geosporum BEG199 were compared using Pearson Chi-Square test at a significance level of $P<0.05$. All the remaining data were analysed using Student's $t$-test at a significance level of $P<0.05$. This test was used to compare means of parameters of the two G. geosporum cultivation lineages within one growth substrate. The data from the mycorrhizal parameters were analysed without including the respective non-inoculated control treatments. All statistical analyses were performed using SPSS 16.0.1 software package (SPSS Inc., Chicago, IL, USA).

\section{Results}

\subsection{Cultivation lineages of Glomus geosporum}

There were no significant differences in the levels of root colonisation of maize and clover inoculated with G. geosporum and grown with or without the stresses of the highly alkaline anthropogenic sediment (Table 2). However, there was a significant increase of 3.1 times in the length of the ERM and of 2.7 times in the number of spores produced by G. geosporum cultivated with the stresses of the sediment, compared with G. geosporum cultivated without the stresses of the sediment.

There were no significant differences between the biomass of maize and clover inoculated with G. geosporum and grown with or without the stresses of the sediment (data not shown).

\subsection{Spore germination test}

There were no significant differences in the percentage of germinated spores between the two G. geosporum cultivation

Table 2

Mycorrhizal parameters of Glomus geosporum after 14 months of cultivation in inert substrate (ISL) and in the original alkaline sediment (OSL).

\begin{tabular}{|c|c|c|c|c|}
\hline Cultivation lineage & $\begin{array}{l}\text { Maize AMF colonisation } \\
(\% \text { RLC) }\end{array}$ & $\begin{array}{l}\text { Clover AMF colonisation } \\
\text { (\% RLC) }\end{array}$ & $\begin{array}{l}\text { Number of spores } \\
\text { (spores } g^{-1} \text { dry substrate) }\end{array}$ & $\begin{array}{l}\text { ERM length } \\
\left(\mathrm{cm} \mathrm{g}^{-1} \text { dry substrate) }\right.\end{array}$ \\
\hline ISL & $63 \pm 4$ & $79 \pm 4$ & $41 \pm 7$ & $184 \pm 43$ \\
\hline OSL & $66 \pm 2$ & $78 \pm 4$ & $110 \pm 12$ & $575 \pm 63$ \\
\hline Student's $t$-test significance & ns & ns & & \\
\hline
\end{tabular}

Values are means $\pm 1 \mathrm{SE}(n=4)$

significant effect at the level of $P<0.01$; ns, non-significant effect; ISL, inert substrate lineage; OSL, original substrate lineage; AMF, arbuscular mycorrhizal fungi; \% RLC, percentage root length colonised; ERM, extraradical mycelium. 


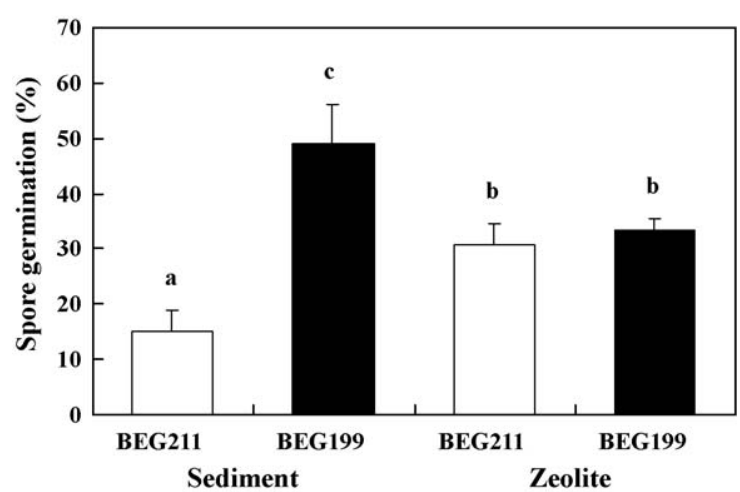

Fig. 1. Percentage of spores of Glomus geosporum lineages (BEG211 and BEG199) that germinated in the alkaline sediment and in zeolite. Values are means $\pm 1 \mathrm{SE}$. The $F$-values of two-way ANOVA were $F_{1,8}=17.0(P<0.01)$ for the Glomus geosporum lineage and $F_{1,8}=12.7(P<0.01)$ for the Glomus geosporum lineage $\times$ germination matrix interaction. There was no significant effect of the germination matrix $(P>0.05)$. Columns marked with different letters differed significantly according to Duncan's Multiple Range test at $P<0.05$. IBG (formerly BEG), International Bank for the Glomeromycota.

lineages (BEG199 and BEG211) germinated in zeolite (Fig. 1). However, there was a significant increase of 3.3 times in the percentage of germinated spores of G. geosporum BEG199 compared with G. geosporum BEG211 germinated in the alkaline sediment.

Spores of G. geosporum BEG211 had a significantly greater percentage of germination in zeolite than in sediment. Conversely, spores of G. geosporum BEG199 had a significantly greater percentage of germination in sediment than in zeolite.

\subsection{DNA analyses of Glomus geosporum lineages}

The LSU D2 region of the rRNA gene was successfully amplified for both cultivation lineages of G. geosporum (BEG199 and BEG211) and a typical product of $460 \mathrm{bp}$ in length was obtained. After PCRSSCP analyses of cloned inserts and sequencing of the representative clones of each PCR-SSCP profile, a total of 13 sequence variants (out of 50 analysed cloned inserts) were obtained for G. geosporum BEG211 (Fig. 2a) and 17 sequence variants (out of 55 analysed cloned inserts) were obtained for G. geosporum BEG199 (Fig. 2b). The frequencies of sequence variants of G. geosporum BEG211 and G. geosporum BEG199 were found to be statistically different (Fig. 2). There were nine sequences detected only in G. geosporum BEG211 and 13 sequences detected only in G. geosporum BEG199. From a total of 26 sequence variants, only four were found simultaneously in both lineages of G. geosporum. All sequence data has been submitted to GenBank under the following accession numbers: $\quad$ BEG211-1 = BEG199-1 (EU931261), BEG2112 = BEG199-2 (EU931262), BEG211-3 = BEG199-3 (EU931263), BEG211-4 = BEG199-4 (EU931264), BEG211-5 (EU931265), BEG211-6 (EU931266), BEG211-7 (EU931267), BEG211-8 (EU931268), BEG211-9 (EU931269), BEG211-10 (EU931270), BEG211-11 (EU931271), BEG211-12 (EU931272), BEG211-13 (EU931273), BEG199-5 (EU931274), BEG199-6 (EU931275), BEG199-7 (EU931276), BEG199-8 (EU931277), BEG199-9 (EU931278), BEG199-10 (EU931279), BEG199-11 (EU931280), BEG199-12 (EU931281), BEG199-13 (EU931282), BEG199-14 (EU931283), BEG199-15 (EU931284), BEG199-16 (EU931285), BEG199-17 (EU931286).

The frequency of sequence variants ranged from 2.0 to $20.0 \%$ for G. geosporum BEG211 and from 1.8 to $20.0 \%$ for G. geosporum BEG199, as calculated with respect to the total number of clones analysed for each isolate (Fig. 2).
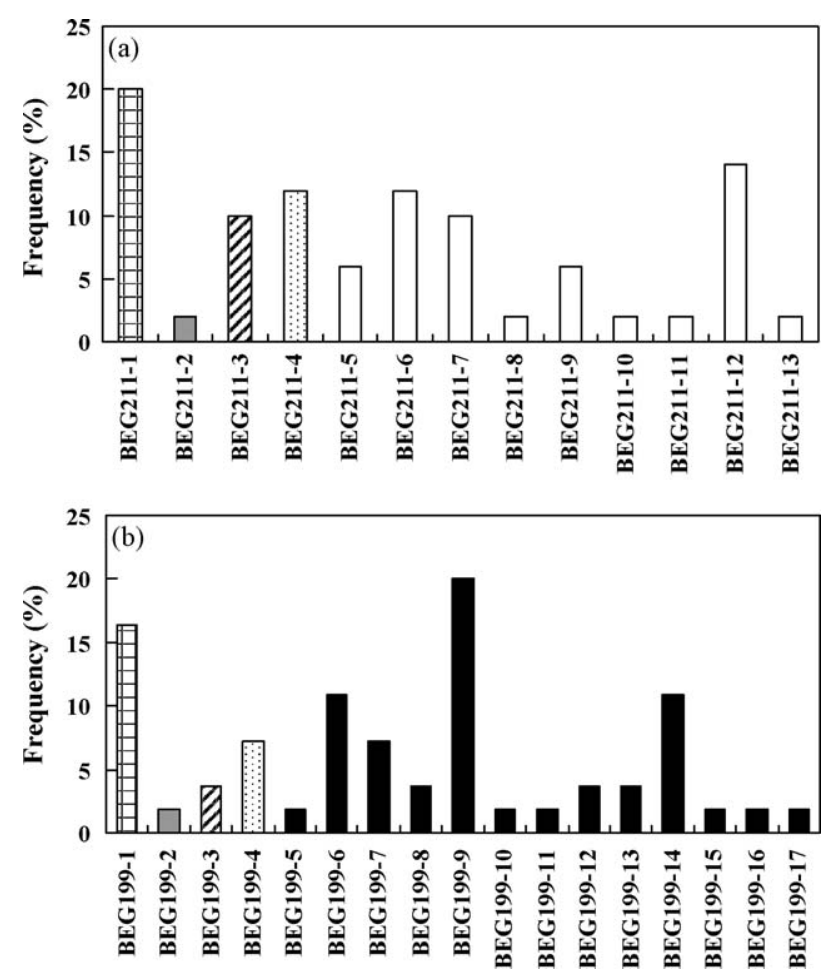

Fig. 2. Frequencies of each sequence variant of Glomus geosporum BEG211 (a) and Glomus geosporum BEG199 (b), calculated as the number of occurrences of a sequence variant divided by the total number of sequences within each Glomus geosporum lineage. Open bars indicate sequences unique to Glomus geosporum BEG211. Black bars indicate sequences unique to Glomus geosporum BEG199. Bars with the same pattern found in (a) and (b) indicate the same sequence found in both Glomus geosporum lineages (BEG211 and BEG199). The frequencies of sequence variants of $G$. geosporum BEG211 and G. geosporum BEG199 were significanty different according to the Pearson Chi-Square test $\left(\chi^{2}=68.7, d f=25, P<0.001\right)$. IBG (formerly BEG), International Bank for the Glomeromycota.

Two of the four common sequence variants had similar frequencies in each lineage of G. geosporum. Both BEG211-1 and BEG199-1 sequences had a high frequency (20.0 and $16.4 \%$, respectively), while BEG211-2 and BEG199-2 sequences had a low frequency ( 2.0 and $1.8 \%$, respectively).

In total, 99 sequences were used for phylogenetic analysis (including those obtained from GenBank). Four hundred and twenty five characters were assessed, 393 (92\%) base positions were variable, of which 31 (8\%) were parsimony-uninformative. Neighbour-joining and maximum parsimony analysis gave largely the same tree topologies. The phylogenetic tree is shown in Fig. 3.

Sequences isolated from both cultivation lineages of $G$. geosporum (BEG199 and BEG211) clustered tightly together on the tree and grouped with other previously published sequences. Sequence BEG211-8 did not group with the main G. geosporum cluster, which included the G. geosporum BEG199 and BEG211 sequences, but this sequence was identical to another previously published G. geosporum sequence (G. geosporum BEG11 AF305005). All sequences obtained in this study from both cultivation lineages of G. geosporum (BEG199 and BEG211) fell within the cluster that included G. coronatum/G. constrictum/G. mosseae/G. geosporum (Fig. 3). No non-glomeromycotan sequences were isolated from the two cultivation lineages of G. geosporum (BEG199 and BEG211).

One sequence from G. geosporum BEG199 and two sequences from G. geosporum BEG211 were identical to previously reported sequences from $G$. geosporum BEG11, originally isolated from Kent, UK. Exact sequence matches were found between BEG199-6 and G. geosporum BEG11 AF304999, BEG211-5 and G. geosporum BEG11 AF305000, BEG211-8 and G. geosporum BEG11 AF305005. 


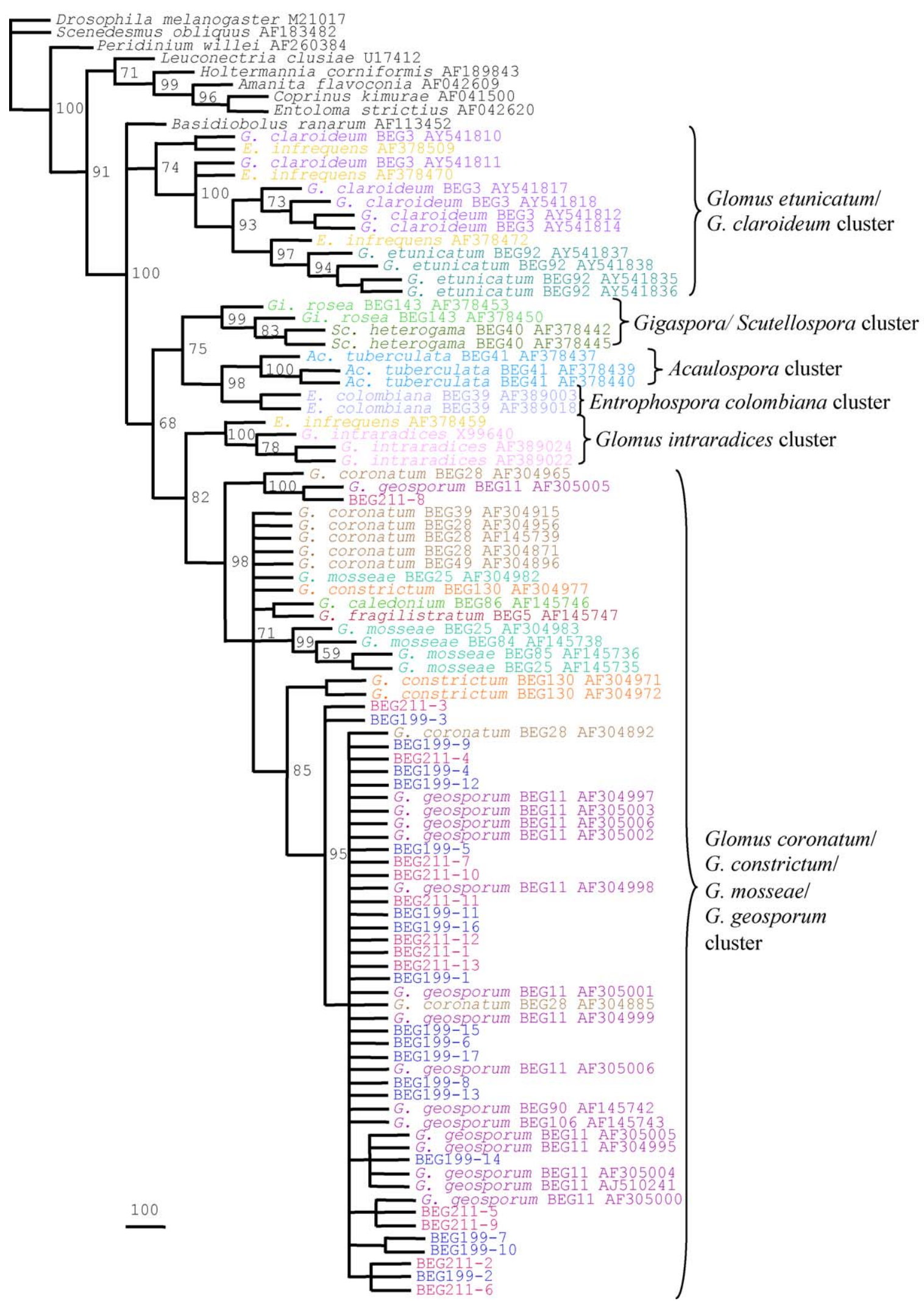

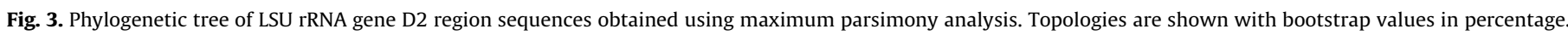

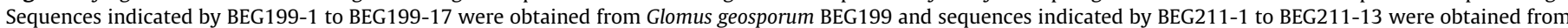

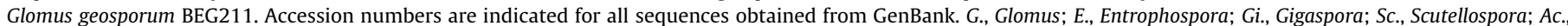
Acaulospora; IBG (formerly BEG), International Bank for the Glomeromycota. 
Table 3

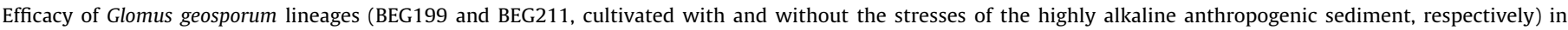
promoting the biomass and leaf phosphorus concentration of Conyza bilbaoana grown in zeolite and in alkaline sediment.

\begin{tabular}{|c|c|c|c|c|c|}
\hline Substrate & Inoculation & Root d. wt (g) & Shoot d. wt (g) & Total d. wt (g) & Leaf $\mathrm{P}$ concentration $\left(\mathrm{mgg}^{-1}\right)$ \\
\hline \multirow[t]{4}{*}{ Zeolite } & Control & $0.049 \mathrm{a}$ & $0.177 \mathrm{a}$ & $0.226 \mathrm{a}$ & nd \\
\hline & G.g. BEG211 & $0.074 \mathrm{ab}$ & $0.289 \mathrm{~b}$ & $0.363 \mathrm{~b}$ & 0.53 \\
\hline & G.g. BEG199 & $0.109 \mathrm{~b}$ & $0.359 \mathrm{c}$ & $0.468 \mathrm{c}$ & 0.64 \\
\hline & Significance & $F_{2,15}=4.4^{*}$ & $F_{2,15}=26.6^{* * *}$ & $F_{2,15}=20.7^{* * * *}$ & ns \\
\hline \multirow[t]{4}{*}{ Sediment } & Control & $0.014 \mathrm{x}$ & $0.034 \mathrm{x}$ & $0.048 \mathrm{x}$ & nd \\
\hline & G.g. BEG211 & $1.221 \mathrm{y}$ & $1.296 \mathrm{y}$ & $2.516 \mathrm{y}$ & 0.78 \\
\hline & G.g. BEG199 & $1.229 \mathrm{y}$ & $1.302 \mathrm{y}$ & $2.531 \mathrm{y}$ & 0.92 \\
\hline & Significance & $F_{2,15}=523.1^{* * * *}$ & $F_{2,15}=225$ & $F_{2,15}=501.8^{* * *}$ & \\
\hline
\end{tabular}

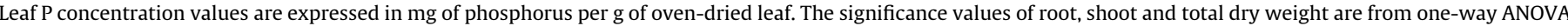

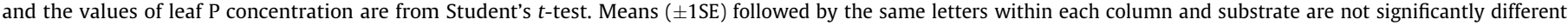

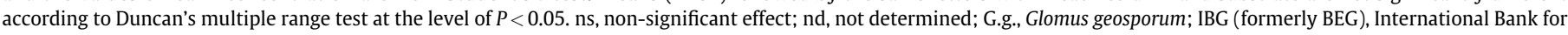
the Glomeromycota; d. wt, dry weight; P, phosphorus.

Significant effect at the level of $P<0.05$.

Significant effect at the level of $P<0.01$.

Significant effect at the level of $P<0.001$.

One sequence from G. geosporum BEG199 (BEG199-9) was identical to a previously reported sequence from $G$. coronatum BEG28 (AF304892).

\subsection{Symbiotic efficacy of Glomus geosporum lineages}

Glomus geosporum BEG199 was more effective than G. geosporum BEG211 in promoting the shoot and total plant biomass of $C$. bilbaoana grown in zeolite. Plants of $C$. bilbaoana inoculated with G. geosporum BEG199 and grown in zeolite had a significant increase of 1.2 times in shoot biomass and of 1.3 times in total biomass compared with those inoculated with $G$. geosporum BEG211 (Table 3).

There were no significant differences in root, shoot and total plant biomass of $C$. bilbaoana grown in alkaline sediment and inoculated with G. geosporum BEG199 or G. geosporum BEG211. However, there was a significant increase of 1.2 times in leaf $P$ concentration of C. bilbaoana plants grown in sediment and inoculated with G. geosporum BEG199, compared with those inoculated with G. geosporum BEG211.

Plants inoculated with either of the $G$. geosporum cultivation lineages (BEG199 and BEG211) produced significantly greater shoot and total plant biomass compared with the non-inoculated control plants, irrespectively of the substrate in which they were grown. Plants inoculated with either of the G. geosporum cultivation lineages (BEG199 and BEG211) produced significantly greater root biomass when grown in sediment, while only plants inoculated with G. geosporum BEG199 produced significantly greater root biomass when grown in zeolite, compared with noninoculated control plants.

Conyza bilbaoana grown in sediment had a high frequency of colonisation assessed 2, 3, 4 and 7 months after inoculation, without significant differences between plants inoculated with $G$. geosporum BEG211 and G. geosporum BEG199 (Fig. 4a). Plants grown in zeolite had their roots colonised to a lesser extent and there were no significant differences in frequency of colonisation between plants inoculated with either of the G. geosporum cultivation lineages at any of the sampling times. Plants inoculated with G. geosporum BEG199, however, had a significantly greater intensity of colonisation than plants inoculated with G. geosporum BEG211 after 4 and 7 months, irrespectively of the growth substrate (Fig. 4b). The arbuscule abundance in the roots of $C$. bilbaoana was significantly greater in plants inoculated with $G$. geosporum BEG199 than in plants inoculated with G. geosporum BEG211 after 3, 4 and 7 months when grown in sediment and after 4 and 7 months when grown in zeolite (Fig. 4c). The vesicle abundance in the roots of $C$. bilbaoana was significantly greater in plants inoculated with G. geosporum BEG199 than in plants inoculated with G. geosporum BEG211, 2 months after inoculation, while the opposite was observed 4 months after inoculation in sediment (Fig. 4d). For plants grown in zeolite there were no significant differences in vesicle abundance in the roots of $C$. bilbaoana inoculated with G. geosporum BEG211 or G. geosporum BEG199. No colonisation by AMF was observed in any of the noninoculated control plants.

The number of spores produced by G. geosporum BEG199 was significantly greater than that of G. geosporum BEG211, 7 months after inoculation, irrespectively of the substrate in which $C$. bilbaoana was grown (Fig. 5a). Seven months after inoculation in sediment, there was an increase of 2.4 times in the number of spores produced by G. geosporum BEG199 compared with that of $G$. geosporum BEG211. Glomus geosporum BEG199 in symbiosis with C. bilbaoana grown in zeolite started to produce spores earlier than G. geosporum BEG211.

The length of the ERM produced in sediment by G. geosporum BEG199 was significantly greater than that of G. geosporum BEG211 at all sampling times (Fig. 5b). There was an increase of 5.8, 2.3, 1.8 and 1.5 times in the length of the ERM produced by G. geosporum BEG199 compared with that of G. geosporum BEG211, assessed 2, 3, 4 and 7 months after inoculation in sediment, respectively. There was a significant increase of 1.4 times in the length of the ERM produced by $G$. geosporum BEG199 compared with that of $G$. geosporum BEG211, 7 months after inoculation in zeolite.

\section{Discussion}

The isolate of Glomus geosporum used in our study showed phenotypic variation in the number of spores and the length of ERM produced after a cultivation period of 14 months. This period corresponded to between two and four generation times of $G$. geosporum indicating that it can alter its phenotype quickly when cultivated with or without the stresses of the sediment.

Spores from both lineages of $G$. geosporum were able to germinate in the two tested substrates in spite of their different edaphic conditions (e.g. different pHs), thus demonstrating plasticity in this G. geosporum isolate (Sylvia and Williams, 1992; Enkhtuya et al., 2000). However, cultivation with or without the stresses of the sediment influenced the germinability of $G$. geosporum spores. When spores were germinated in the sediment, a reduction and an increase in \% germination was observed in $G$. geosporum BEG211 and in G. geosporum BEG199, respectively, compared with spores germinated in zeolite. The stresses of the sediment (e.g. extremely high $\mathrm{pH}$ ) might have inhibited spore germination of G. geosporum BEG211 and stimulated spore 

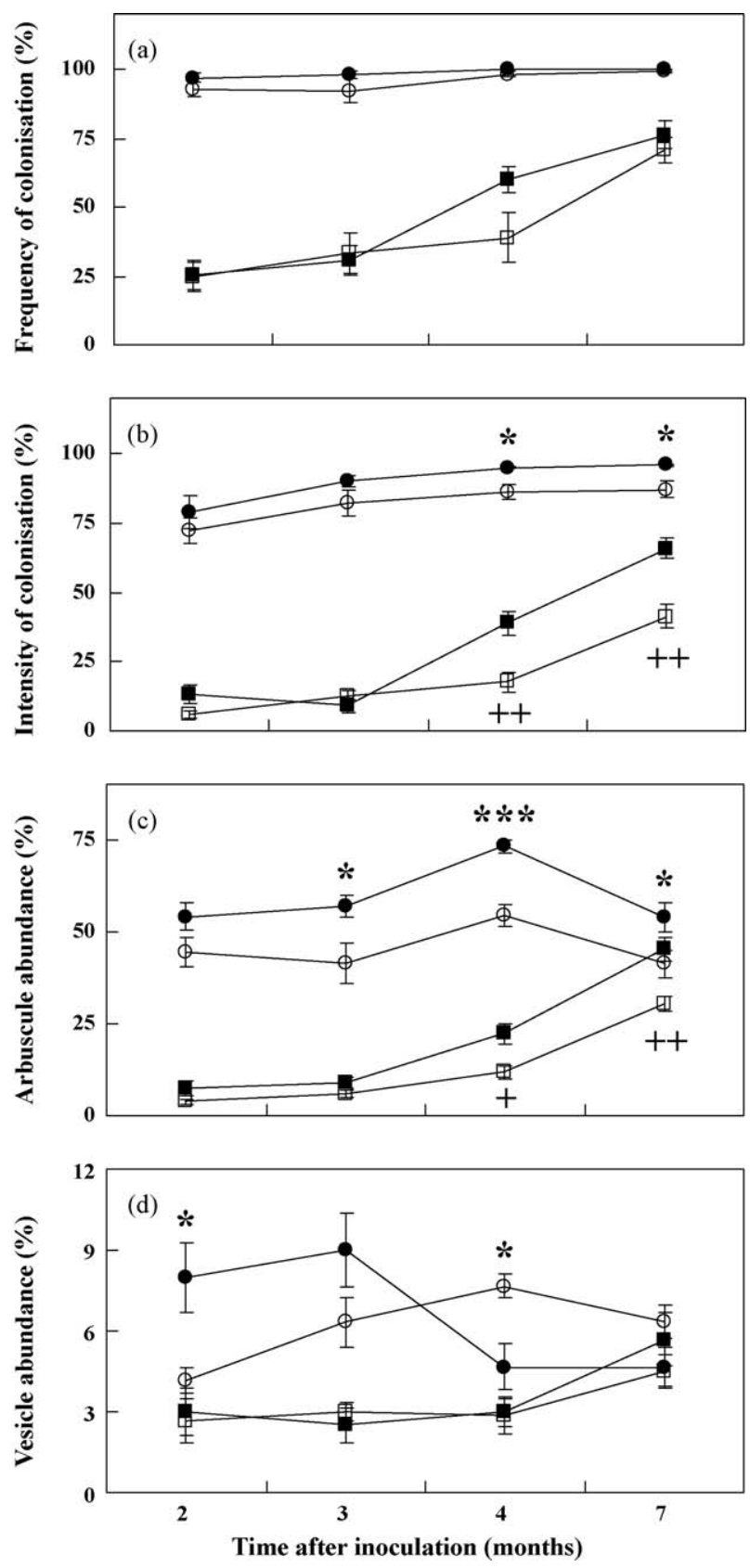

Fig. 4. The colonisation of Conyza bilbaoana by Glomus geosporum BEG199 (closed symbols) and Glomus geosporum BEG211 (open symbols) grown in zeolite (squares) or in alkaline sediment (circles) assessed 2, 3, 4 and 7 months after inoculation. (a) Frequency of colonisation (F\%) expressed as the percentage of the root length colonised by arbuscular mycorrhizal fungi (b) intensity of mycorrhizal fungi colonisation $(M \%)$ in the root system (c) arbuscule abundance $(A \%)$ expressed as the percentage of the root length occupied by arbuscules (d) vesicle abundance $(V \%)$ expressed as the percentage of the root length occupied by vesicles. Values are means $\pm 1 \mathrm{SE}(n=6)$. Means of the two G. geosporum cultivation lineages (BEG199 and BEG211) were compared within one growth substrate using Student's $t$-test Significant effect at the level of ${ }^{*} P<0.05$ and ${ }^{* *} P<0.01$ for the alkaline sediment. Significant effect at the level of ${ }^{+} P<0.05$ and ${ }^{++} P<0.01$ for zeolite. Data points without symbols indicate no significant difference between the two $G$. geosporum cultivation lineages within one growth substrate.

germination of G. geosporum BEG199. It is known that environmental factors such as $\mathrm{pH}$ influence the germination of spores of AMF (Dodd and Jeffries, 1989; Giovannetti, 2000) and that they usually germinate better under similar environmental conditions to those of the habitat from where they were isolated (Sylvia and Williams, 1992; Clark, 1997). Since the pH of zeolite was ca. $5 \mathrm{pH}$
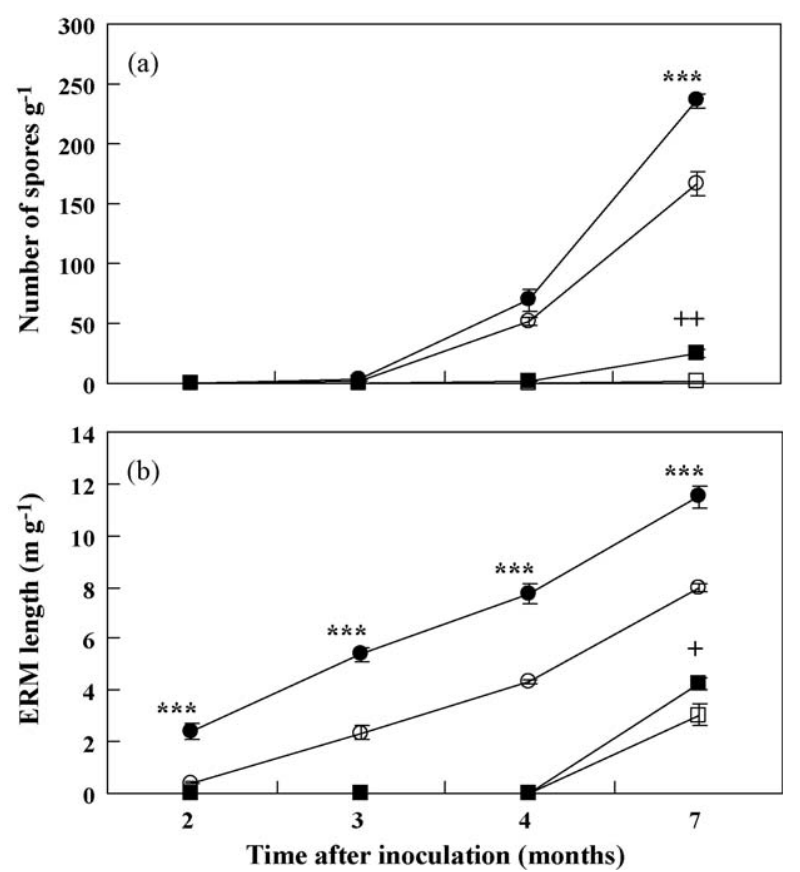

Fig. 5. Spore number (a) and length of the extraradical mycelium (b) of Glomus geosporum BEG199 (closed symbols) and Glomus geosporum BEG211 (open symbols) in symbiosis with Conyza bilbaoana grown in zeolite (squares) and in alkaline sediment (circles) assessed 2, 3, 4 and 7 months after inoculation. Values are means $\pm 1 \mathrm{SE}(n=6)$. Means of the two G. geosporum cultivation lineages (BEG199 and BEG211) were compared within one growth substrate using Student's $t$-test. Significant effect at the level of ${ }^{* * *} P<0.001$ for the alkaline sediment. Significant effect at the level of ${ }^{+} P<0.05$ and ${ }^{++} P<0.01$ for zeolite. Data points without symbols indicate no significant difference between the two $G$. geosporum cultivation lineages within one growth substrate. ERM, extraradical mycelium.

units lower than that of the sediment, this could explain the increase in germination in G. geosporum BEG199 spores in the alkaline sediment compared with the germination in zeolite. The reduction in spore germination capacity of $G$. geosporum BEG211 in sediment was possibly due to its 14 months of cultivation in zeolite, indicating that AMF might quickly lose gained-tolerance to environmental stresses when maintained without the selective pressure of those stresses (Weissenhorn et al., 1994; Vosátka and Dodd, 2002; Malcová et al., 2003). However, after cultivation without the stresses of the sediment, spores of G. geosporum still germinated in sediment showing that the capacity to germinate was not completely lost, i.e. tolerance to the stresses of the sediment was partly maintained.

The variation between G. geosporum cultivated with or without the stresses of the sediment was also found at the genetic level. Very little data exist on within-isolate genetic variation in AMF (Sanders, 2004) and only few studies have carried out the extensive sequencing that is necessary to detect most of the variation observed in AMF isolates (e.g. Clapp et al., 2001; Rodriguez et al., 2001; Robinson, 2005; Rodriguez et al., 2005). In the present study we obtained 13 sequence variants in G. geosporum BEG211 and 17 sequence variants in G. geosporum BEG199. This magnitude of sequence polymorphism was similar to that found in other investigations on the LSU rRNA gene of G. geosporum isolates, i.e., 14 sequence variants were obtained by Clapp et al. (2001) in $G$. geosporum BEG11 and 15 sequence variants were obtained by Kuhn et al. (2001) in G. geosporum BEG18. This sequence diversity found in our $G$. geosporum isolate supports previous observations of high levels of polymorphisms present in the rRNA genes of AMF spores (Sanders et al., 1995; Pringle et al., 2000; Clapp et al., 2001; Kuhn et al., 2001; Rodriguez et al., 2001; Robinson, 2005; Rodriguez et al., 2005). 
Although multiple sequence variants occur in our G. geosporum cultivation lineages (BEG199 and BEG211), they clustered tightly together on the phylogenetic tree and grouped with other previously published sequences from other isolates of G. geosporum isolated from UK and Denmark. This indicates that sequence variants are closely related together within the species group of $G$. geosporum. All our sequences from $G$. geosporum fell within the cluster that included $G$. coronatum/G. constrictum/G. mosseae/G. geosporum, confirming the findings of Clapp et al. (2001) and Rodriguez et al. (2005) that these four species could be part of a genetic continuum.

We found three sequences from our $G$. geosporum cultivation lineages (BEG199 and BEG211), originally isolated from an anthropogenic sediment in Northern Portugal, to be identical to previously reported sequences from G. geosporum BEG11, originally isolated from agricultural land in Kent, UK. Therefore, isolates from the same AMF species can share some sequence variants even when isolated from very different environments and geographical locations.

The studies that have addressed the frequency of sequence variants within AMF isolates indicate that those frequencies are not equal (Kuhn et al., 2001; Clapp et al., 2001; Rodriguez et al., 2005). In the present work we also found that the sequence variants were not equal for each of the cultivation lineages of $G$. geosporum and that their frequencies were significantly different. The influence of environmental conditions on gene sequence diversity in AMF was studied by Robinson (2005) who analysed the sequence diversity and frequency of the LSU rRNA gene of $G$. mosseae BEG185 cultivated under different environmental conditions. A change from high to low light intensity resulted in a change in diversity and frequency of sequences present in spores and in the emergence of new dominant sequences. Some sequence variants were always present in G. mosseae BEG185 spores irrespective of environmental shifts.

In the work of Robinson (2005) and in the present study some sequence variants seem to become more prevalent under certain environmental conditions, while others remain relatively unaffected in spores of AMF isolates irrespective of the environmental conditions under which they are cultivated. Multiple sequences in AMF spores may be part of a mechanism for adapting to new environments, in which certain gene sequence variants become more frequent when the AMF encounters certain environmental conditions.

Clapp et al. (2001) also studied the genetic diversity of a $G$. coronatum isolate maintained in different laboratories and showed that the relative frequency of several rRNA gene sequences decreased to levels that were undetectable in some cultivation lineages but were retained at higher frequencies in others. As each spore may contain thousands of nuclei, each with multiple copies of the rRNA gene cluster, it is not known if sequence variants that were not detected had been lost from the gene pool, or had simply dropped in frequency such that they were no longer detected using the sample sizes employed in these experiments.

Besides genetic variation, phenotypic and functional variation was also found between $G$. geosporum cultivated with or without the stresses of the highly alkaline sediment after inoculation in the target plant C. bilbaoana. Glomus geosporum BEG199 was more effective than G. geosporum BEG211 in promoting the shoot and total plant biomass of $C$. bilbaoana grown in zeolite and in increasing the leaf $\mathrm{P}$ concentration of $C$. bilbaoana grown in sediment. These results indicate that the symbiotic efficacy of $G$. geosporum decreased when cultivated without the stresses of the sediment from where it was originally isolated. A decrease in tolerance to heavy metals and in the ability to support plant growth was also reported by Malcová et al. (2003) and Rydlová and
Vosátka (2003) in Glomus spp. after cultivation without the stress of heavy metals.

Munkvold et al. (2004) have demonstrated that the choice of AMF isolate from a species can be just as important as the choice of the species for the outcome of studies on AMF-plant symbioses. Our results, in accordance with Malcová et al. (2003) and Rydlová and Vosátka (2003) show that environmental conditions under which AMF isolates are cultivated, particularly the choice of growth substrate, can also be determinant for their functionality and, consequently, for the outcome of a study.

Glomus geosporum BEG211 and BEG199 had a similar frequency of colonisation in the roots of $C$. bilbaoana. The vesicle abundance in the roots of $C$. bilbaoana did not differ significantly except 2 and 4 months after inoculation in sediment. However, G. geosporum BEG199 had a greater intensity of colonisation and arbuscule abundance in the roots of C. bilbaoana than G. geosporum BEG211, especially 4 and 7 months after inoculation. Overall, G. geosporum BEG199 produced a greater number of spores and ERM than $G$. geosporum BEG211. These results show that variation between the two cultivation lineages was not only found at the functional level, but also at the phenotypic level.

Our results support the hypothesis of Sanders (2002) that environmental heterogeneity could act as a selection on nuclear genotypes creating genetic variation in AMF.

We hypothesise that the genetic variation found between the two cultivation lineages could have led to the variation observed in their phenotypes [as shown by the study of Koch et al. (2004)] and could have in turn contributed to the functional differences between the two G. geosporum cultivation lineages. Studies including genes other than rRNA genes, especially those that code for proteins and are involved in cell function or the establishment and functioning of the symbiosis, would contribute to improve our knowledge on the relationship between genetic and functional diversity in AMF.

This is the first detailed study to report genetic, phenotypic and functional variation in different cultivation lineages of a single isolate of AMF, sub-cultured under different environmental conditions. Whether such variation exists in other isolates of AMF remains unclear and more studies with isolates from other species and genera isolated from different environments (anthropogenic, degraded and natural ecosystems) and subjected to different stresses, are required.

Our results have implications for the production and improvement of commercial inoculum of AMF and for the maintenance of AMF cultures. There is an ongoing concern among inoculum producers of whether the stability of tolerance in AMF isolates to a given stress, which it was screened for, is maintained following sub-culturing (Vosátka and Dodd, 2002). Currently, in the most commonly used methods for the production of inoculum of AMF, inert substrates or artificial media are used (Gianinazzi and Vosátka, 2004). In our study, we have shown that AMF can quickly lose some of their symbiotic efficacy when cultivated without edaphic stresses of the environment from where they are originally isolated.

We therefore recommend that inoculum of AMF should be produced in substrates or media containing the original edaphic stresses, especially the production of inoculum of AMF isolates from extreme environments with very strong environmental stresses. This practice should be adopted for inoculum production not only for commercial purposes, but also for scientific research.

\section{Acknowledgements}

This work was supported by the Project MICOMETA - POCI/ AMB/60131/2004 financed by Medida V.4-Acção V.4.1 of Programa Operacional da Ciência e Inovação 2010 (Fundação para a Ciência e Tecnologia) and Mychintec (ICA4-CT-2000-30014) Project from 
the EU INCO-DEV FP5 programme. The authors wish to thank Fundação para a Ciência e a Tecnologia and Fundo Social Europeu (III Quadro Comunitário de Apoio), research grants of R. S. Oliveira (SFRH/BPD/23749/2005) and M.F. Carvalho (SFRH/BPD/44670/ 2008).

\section{References}

Allen, M.F., Moore Jr.T.S., Christensen, M., Stanton, N., 1979. Growth of vesiculararbuscular-mycorrhizal and nonmycorrhizal Bouteloua gracilis in a defined medium. Mycologia 71, 666-669.

Börstler, B., Raab, P.A., Thiéry, O., Morton, J.B., Redecker, D., 2008. Genetic diversity of the arbuscular mycorrhizal fungus Glomus intraradices as determined by mitochondrial large subunit rRNA gene sequences is considerably higher than previously expected. New Phytol. 180, 452-465.

Brundrett, M., 1991. Mycorrhizas in natural ecosystems. Adv. Ecol. Res. 21, 171313.

Brundrett, M., Juniper, S., 1995. Non-destructive assessment of spore germination of VAM fungi and production of pot cultures from single spores. Soil Biol. Biochem. 27, 85-91.

Brundrett, M., Melville, L., Peterson, R.L., 1994. Practical Methods in Mycorrhizal Research. Mycologue Publications, Waterloo.

Clapp, J.P., Rodriguez, A., Dodd, J.C., 2001. Inter- and intra-isolate rRNA large subunit variation in Glomus coronatum spores. New Phytol. 149, 539-554.

Clark, R.B., 1997. Arbuscular mycorrhizal adaptation, spore germination, root colonization, and host plant growth and mineral acquisition at low pH. Plant Soil 192, 15-22.

Corradi, N., Croll, D., Colard, A., Kuhn, G., Ehinger, M., Sanders, I.R., 2007. Gene copy number polymorphisms in an arbuscular mycorrhizal fungal population. Appl. Environ. Microbiol. 73, 366-369.

Corradi, N., Kuhn, G., Sanders, I.R., 2004. Monophyly of $\beta$-tubulin and $H^{+}$-ATPase gene variants in Glomus intraradices: consequences for molecular evolutionary studies of AM fungal genes. Fungal Genet. Biol. 41, 262-273.

Dodd, J.C., Jeffries, P., 1989. Effects of herbicides on three vesicular-arbuscular fungi associated with winter wheat (Triticum aestivum L.). Biol. Fert. Soils 7, 113-119.

Enkhtuya, B., Rydlová, J., Vosátka, M., 2000. Effectiveness of indigenous and nonindigenous isolates of arbuscular mycorrhizal fungi in soils from degraded ecosystems and man-made habitats. Appl. Soil Ecol. 14, 201-211.

Feldmann, F., 1998. The strain-inherent variability of arbuscular mycorrhizal effectiveness. Symbiosis 25, 131-143.

Felsenstein, J., 1985. Confidence limits on phylogenies: an approach using the bootstrap. Evolution 39, 783-791.

Gianinazzi, S., Vosátka, M., 2004. Inoculum of arbuscular mycorrhizal fungi for production systems: science meets business. Can. J. Bot. 82, 1264-1271.

Giovannetti, M., 2000. Spore germination and pre-symbiotic mycelial growth. In: Kapulnik, Y., Douds, D.D. (Eds.), Arbuscular Mycorrhizas: Physiology and Function. Kluwer Academic Publishers, Dordrecht, pp. 47-68.

Giovannetti, M., Mosse, B., 1980. An evaluation of techniques for measuring vesicular arbuscular mycorrhizal infection in roots. New Phytol. 84, 489-500.

Helgason, T., Watson, I.J., Young, J.P.W., 2003. Phylogeny of the Glomerales and Diversisporales (Fungi: Glomeromycota) from actin and elongation factor 1alpha sequences. FEMS Microbiol. Lett. 229, 127-132.

Jakobsen, I., Abbott, L.K., Robson, A.D., 1992. External hyphae of vesicular-arbuscular mycorrhizal fungi associated with Trifolium subterraneum L. 1: Spread of hyphae and phosphorus inflow into roots. New Phytol. 120, 371-380.

Koch, A.M., Croll, D., Sanders, I.R., 2006. Genetic variability in a population of arbuscular mycorrhizal fungi causes variation in plant growth. Ecol. Lett. 9, $103-110$.

Koch, A., Kuhn, G., Fontanillas, P., Fumagalli, L., Goudet, J., Sanders, I.R., 2004. High genetic variability and low local diversity in a population of arbuscular mycorrhizal fungi. Proc. Natl. Acad. Sci. U. S. A. 101, 2369-2374.

Koide, R.T., Li, M., 1989. Appropriate controls for vesicular-arbuscular mycorrhiza research. New Phytol. 111, 35-44.

Kuhn, G., Hijri, M., Sanders, I.R., 2001. Evidence for the evolution of multiple genomes in arbuscular mycorrhizal fungi. Nature 414, 745-748.

Lloyd-MacGilp, S.A., Chambers, S.M., Dodd, J.C., Fitter, A.H., Walker, C., Young, J.P.W., 1996. Diversity of the ribosomal internal transcribed spacers within and among isolates of Glomus mosseae and related mycorrhizal fungi. New Phytol. 133, 103-111.

Malcová, R., Rydlová, J., Vosátka, M., 2003. Metal-free cultivation of Glomus sp. BEG 140 isolated from Mn-contaminated soil reduces tolerance to Mn. Mycorrhiza 13, 151-157.

Munkvold, L., Kjoller, R., Vestberg, M., Rosendahl, S., Jakobsen, I., 2004. High functional diversity within species of arbuscular mycorrhizal fungi. New Phytol. $164,357-364$.

Novozamsky, I., Houba, V.J.G., Van Eck, R., Van Vark, W., 1983. A novel digestion technique for multi-element plant analysis. Commun. Soil Sci. Plant Anal. 14, 239-248.
Oliveira, R.S., Castro, P.M.L., Dodd, J.C., Vosátka, M., 2005a. Synergistic effect of Glomus intraradices and Frankia spp. on the growth and stress recovery of Alnus glutinosa in an alkaline anthropogenic sediment. Chemosphere 60, 1462-1470.

Oliveira, R.S., Dodd, J.C., Castro, P.M.L., 2001. The mycorrhizal status of Phragmites australis in several polluted soils and sediments of an industrialised region of Northern Portugal. Mycorrhiza 10, 241-247.

Oliveira, R.S., Vosátka, M., Dodd, J.C., Castro, P.M.L., 2005b. Studies on the diversity of arbuscular mycorrhizal fungi and the efficacy of two native isolates in a highly alkaline anthropogenic sediment. Mycorrhiza 16, 23-31.

Page, R.D.M., 1996. TREEVIEW: an application to display phylogenetic trees on personal computers. Comput. Appl. Biosci. 12, 357-358.

Phillips, J.M., Hayman, D.S., 1970. Improved procedures for clearing roots and staining parasitic and vesicular-arbuscular mycorrhizal fungi for rapid assessment of infection. Trans. Br. Mycol. Soc. 55, 158-161.

Pringle, A., Moncalvo, J.M., Vilgalys, R., 2000. High levels of variation in ribosomal DNA sequences within and among spores of a natural population of the arbuscular mycorrhizal fungus Acaulospora colossica. Mycologia 92, 259-268.

Robinson, L., 2005. Environmental influences on genomic diversity on Chinese isolate of AMF. MSc. Thesis. University of Kent, Canterbury, UK.

Rodriguez, A., Clapp, J.P., Robinson, L., Dodd, J.C., 2005. Studies on the diversity of the distinct phylogenetic lineage encompassing Glomus claroideum and Glomus etunicatum. Mycorrhiza 15, 33-46.

Rodriguez, A., Dougall, T., Dodd, J.C., Clapp, J.P., 2001. The large subunit ribosomal RNA genes of Entrophospora infrequens comprise sequences related to two different glomalean families. New Phytol. 152, 159-167.

Rydlová, J., Vosátka, M., 2003. Effect of Glomus intraradices isolated from $\mathrm{Pb}$ contaminated soil on $\mathrm{Pb}$ uptake by Agrostis capillaris is changed by its cultivation in a metal-free substrate. Folia Geobot. 38, 155-165.

Saitou, N., Nei, M., 1987. The neighbor-joining method: a new method for reconstructing phylogenetic trees. Mol. Biol. Evol. 4, 406-425.

Sanders, I.R., 2002. Ecology and evolution of multigenomic arbuscular mycorrhizal fungi. Am. Nat. 160, S128-S141.

Sanders, I.R., 2004. Intraspecific genetic variation in arbuscular mycorrhizal fungi and its consequences for molecular biology, ecology, and development of inoculum. Can. J. Bot. 82, 1057-1062.

Sanders, I.R., Alt, M., Groppe, K., Boller, T., Wiemken, A., 1995. Identification of ribosomal DNA polymorphisms among and within spores of the Glomales: application to studies on the genetic diversity of arbuscular mycorrhizal fungal communities. New Phytol. 130, 419-427.

Smith, S.E., Read, D.J., 2008. Mycorrhizal Symbiosis. Academic Press, Cambridge.

Sudová, R., Jurkiewicz, A., Turnau, K., Vosátka, M., 2007. Persistence of heavy metal tolerance of the arbuscular mycorrhizal fungus Glomus intraradices under different cultivation regimes. Symbiosis 43, 71-81.

Swofford, D.L., 1999. PAUP*. Phylogenetic Analysis Using Parsimony (*And Other Methods) Sinauer, Sunderland.

Sylvia, D.M., Williams, S.E., 1992. Vesicular-arbuscular mycorrhizae and environmental stresses. In: Bethlenfalvay, G.J., Linderman, R.G. (Eds.), Mycorrhizae in Sustainable Agriculture. ASA, Madison, pp. 101-124.

Thompson, J.D., Gibson, T.J., Plewniak, F., Jeanmougin, F., Higgins, D.G., 1997. The CLUSTAL_X windows interface: flexible strategies for multiple sequence alignment aided by quality analysis tools. Nucleic Acids Res. 25, 4876-4882.

Trouvelot, A., Kough, J.L., Gianinazzi-Pearson, V., 1986. Mesure du taux de mycorhization VA d'un système radiculaire. Recherche de méthodes d'estimation ayant une signification fonctionnelle. In: Gianinazzi-Pearson, V., Gianinazzi, S. (Eds.), Physiological and Genetical Aspects of Mycorrhizae. INRA Press, Paris, pp. 217-221.

van der Heijden, M.G.A., Klironomos, J.N., Ursic, M., Moutoglis, P., Streitwolf-Engel, R., Boller, T., Wiemken, A., Sanders, I.R., 1998. Mycorrhizal fungal diversity determines plant biodiversity, ecosystem variability and productivity. Nature 396, 69-72.

Van Tuinen, D., Jacquot, E., Zhao, B., Gollotte, A., Gianinazzi-Pearson, V., 1998. Characterization of root colonization profiles by a microcosm community of arbuscular mycorrhizal fungi using 25S rDNA-targeted nested PCR. Mol. Ecol. 7, 879-887.

von Alten, H., Blal, B., Dodd, J.C., Feldmann, F., Vosátka, M., 2002. Quality control of arbuscular mycorrhizal fungi inoculum in Europe. In: Gianinazzi, S., Schuepp, H., Barea, J.M., Haselwandter, K. (Eds.), Mycorrhizal Technology in Agriculture. Birkhauser Verlag, Basel, pp. 281-296.

Vosátka, M., Dodd, J.C., 2002. Ecological considerations for successful application of arbuscular mycorrhizal fungi inoculum. In: Gianinazzi, S., Schuepp, H., Barea, J.M., Haselwandter, K. (Eds.), Mycorrhizal Technology in Agriculture. Birkhause Verlag, Basel, pp. 235-247.

Walinga, I., Van Vark, W., Houba, V.J.G., van der Lee, J.J., 1989. Plant Analysis Procedures (Soil and Plant Analysis, Part 7). Syllabus, Wageningen.

Weissenhorn, I., Glashoff, A., Leyval, C., Berthelin, J., 1994. Differential tolerance to $\mathrm{Cd}$ and $\mathrm{Zn}$ of arbuscular mycorrhizal (AM) fungal spores isolated from heavy metal-polluted and unpolluted soils. Plant Soil 167, 189-196.

Wyss, P., Bonfante, P., 1993. Amplification of genomic DNA of arbuscular-mycorrhizal (AM) fungi by PCR using short arbitrary primers. Mycol. Res. 11, 13511357. 